\title{
Sexual dysfunction in females with depression: a cross- sectional study
}

\author{
Disfunção sexual em mulheres com depressão: um estudo transversal \\ Krishnankutty Sreelakshmy, ${ }^{1}$ Rajmohan Velayudhan, ${ }^{2}$ Deepak Kuriakose, ${ }^{2}$ Rema Nair $^{1}$
}

\begin{abstract}
Introduction: Female sexual dysfunction (FSD) in depression albeit common is strikingly understudied. The condition, if addressed properly, can be readily cured, improving the quality of life of the patient.

Methods: A consecutive sample of drug-naïve married female patients with depression was assessed. Depression was diagnosed using the Structured Clinical Interview for DSM-IV Axis I Disorders (SCID-I). Depression severity was assessed using the Hamilton Depression Rating Scale (HAM-D), and sexual dysfunction, the Female Sexual Function Index (FSFI).

Results: Sexual dysfunction was found in $90 \%$ of the patients in our study. Patients with medical comorbidities showed a significant decrease in the desire subset of the FSFI (MannWhitney $U=11.0, p=0.009$ ), however there was no significant association with other subsets. Patients who expressed passive death wishes had higher scores on all indicators of sexual function and a significantly higher score in the orgasm subset of the FSFI (Mann-Whitney $U=11.0, p=0.009$ ).

Conclusion: The study showed a high prevalence of FSD in depressed females regardless of type and severity of depression. Depression with medical comorbidities was associated with a significant decrease in desire. Patients who expressed passive death wishes showed improved sexual function and significantly better orgasm.
\end{abstract}

Keywords: Depression, sexual dysfunction, women's mental health, orgasmic dysfunction.

\section{Resumo}

Introdução: Disfunção sexual feminina (DSF) na depressão, apesar de comum, é pouco estudada. Se tratada adequadamente, a condição pode ser prontamente curada, aumentando a qualidade de vida da paciente.

Métodos: Foi avaliada uma amostra consecutiva de mulheres casadas, virgens de tratamento, com depressão. A depressão foi diagnosticada utilizando a Structured Clinical Interview for DSM-IV Axis I Disorders (SCID-I). A gravidade da depressão foi avaliada utilizando a Escala de Avaliação de Depressão de Hamilton (HAM-D), e a disfunção sexual, com o Índice da Função Sexual Feminina (Female Sexual Function Index, FSFI).

Resultados: Foi observada disfunção sexual em $90 \%$ das pacientes do estudo. As pacientes com comorbidades médicas mostraram uma diminuição significativa no subdomínio desejo da FSFI (Mann-Whitney $U=11,0, p=0,009$ ), porém não houve associação significativa com os outros subdomínios. Pacientes que expressaram desejos passivos de morte apresentaram escores mais altos em todos os indicadores de função sexual e um escore significativamente mais alto no subdomínio orgasmo da FSFI (Mann-Whitney $U=11,0, p=0,009$ ).

Conclusão: $O$ estudo revelou uma alta prevalência de DSF em mulheres deprimidas, independentemente do tipo e da severidade da depressão. A depressão com comorbidades médicas foi associada a uma diminuição significativa do desejo. Pacientes que expressaram desejos passivos de morte mostraram função sexual melhor e orgasmo significativamente melhor.

Descritores: Depressão, disfunção sexual, saúde mental das mulheres, disfunção orgásmica.

\footnotetext{
${ }^{1}$ Department of Obstetrics and Gynaecology, Sree Mookambika Institute of Medical Sciences, Padanilam, Kulasekharam, Tamil Nadu, India. ${ }^{2}$ Department of Psychiatry, MES Medical College, Perintalmanna, Malappuram, Kerala, India.

Submitted Oct 12 2016, accepted for publication Mar 082017.

Suggested citation: Sreelakshmy R, Velayudhan R, Kuriakose D, Nair R. Sexual dysfunction in females with depression: a cross-sectional study. Trends Psychiatry Psychother. 2017;39(2):106-109. http://dx.doi.org/10.1590/2237-6089-2016-0072
} 


\section{Introduction}

Female sexual dysfunction (FSD), although common, is mostly underreported and understudied. The Indian scenario is no different. There are only very few studies examining FSD, and only one study dealing with FSD in depression. ${ }^{1}$ FSD is a multifactorial condition with biological and psychosocial components.

The sexual dysfunctions most commonly observed in Indian women are loss of sexual desire, impaired arousal, lubrication, and delayed orgasm. ${ }^{1}$ A national survey conducted in the United States showed that a third of women lack sexual interest and nearly a fourth do not experience orgasm. ${ }^{2}$ Another study showed that approximately $20 \%$ of women report lubrication difficulties and $20 \%$ find sex not pleasurable. For many women, sexual dysfunction is physically disconcerting, emotionally distressing and socially disruptive. ${ }^{3}$

Loss of sexual desire itself may be the presenting complaint of depression and low sexual desire may precede depression. Studies show that sexual dysfunction is more prevalent in depressive than nondepressive women. ${ }^{2}$ Loss of sexual desire is more common than disorders of arousal and orgasm. ${ }^{4}$ In another study, hypoactive sexual desire disorder was the most common dysfunction seen in depressive patients. ${ }^{4-6}$ The only study conducted in India showed a $67.34 \%$ rate of clinical sexual dysfunction. ${ }^{1}$

The current study attempts to determine the prevalence of sexual dysfunction in drug-naïve married female patients in the reproductive age group diagnosed with major depressive disorder (MDD) and those with recurrent episodes of MDD. The study aims to examine the association of different sociodemographic and clinical factors with FSD.

\section{Materials and methods}

The study was conducted in the obstetrics and gynecology outpatient department of a rural tertiary care hospital in Kerala and in a rural tertiary care hospital in Tamil Nadu, over a 6-month period, from May 1st to October 31st 2015. The study was approved by the local institutional ethics committee.

Drug-naïve married female patients consecutively seen at the services, aged between 18 and 45 years, were selected based on their willingness to participate and provide written informed consent. Patients with a first episode of MDD and those with recurrent episodes of MDD with no drug exposure in the last 4 weeks were included in the study. Patients with coexisting organic mental disorders, head injury, stroke, mental retardation, and other comorbid psychiatric condition were excluded.

Patients were evaluated clinically and referred to cross-consultation with required departments where necessary to rule out the possibility of organic pathology. All participants with suspected mental retardation were subjected to intelligence quotient (IQ) assessment and excluded if the result was below 90. Patients with an established organic cause for sexual dysfunction or in whom sexual dysfunction could be attributable to another physical condition were also excluded.

Sociodemographic details, depression symptom checklist and other clinical data were collected using a semi-structured questionnaire designed specifically for this study. The questionnaire was not based on any validated instrument. Clinical data included medical, obstetric and gynecological disorders. All patients with suspected depression were then evaluated by the psychiatry department and were diagnosed using the Structured Clinical Interview for DSM-IV Axis I Disorders (SCID-I). ${ }^{7}$ Depression severity was assessed using the Hamilton Depression Rating Scale (HAM-D), ${ }^{8}$ and sexual dysfunction, the Female Sexual Function Index (FSFI). ${ }^{9}$

FSFI is a questionnaire consisting of 19 questions that assess the patient's sexual functions in terms of five domains, namely, desire, arousal, lubrication, orgasm, satisfaction and pain. Each domain is assigned separate scores, and the total net score is obtained by adding up the individual scores.

The data collected were analyzed using nonparametric chi-square and Mann-Whitney $U$ tests. All tests were performed using the Statistical Package for the Social Sciences (SPSS) version 17 for Windows.

\section{Results}

Of a total of 1,643 patients screened in the gynecology department, 214 suspected cases were referred to psychiatric evaluation and only 142 of these patients sought the psychiatry department. Of these 142 drug-naïve women suspected to have depression ( 83 from first site and 59 from second site), 84 (59.15\%) were in the reproductive age group. Thirty-two patients $(38.09 \%)$ refused to participate in the study and nine were excluded because they did not meet the diagnostic criteria for MDD on SCID. Finally, three patients did not complete the FSFI and had to be excluded. As a result, 40 patients comprised the final sample based on inclusion and exclusion criteria.

Mean age of the study population was 37.7 years (21-45). Half of the patients were of low and the other half of middle socioeconomic status. Twenty percent had 
completed elementary education, $70 \%$ high school, and $10 \%$ higher education. Ninety percent were housewives. Forty percent of them had single-episode MDD and $60 \%$ recurrent episodes of MDD. Forty percent had psychotic symptoms, while $30 \%$ had passive death wishes and $30 \%$ had medical comorbidities.

The mean number of depressive episodes was 3 (standard deviation $[S D]=2.08$ ), and the mean duration of episodes, 3.9 months $(S D=1.68)$. Mean duration of illness was 31 months ( $S D=29.1)$, with single-episode MDD having a total illness duration of 4.2 months $(S D=2.0-7)$ and recurrent episodes having a total duration of 49.5 months $(S D=23.9)$. The mean HAM-D score was $25.05(S D=5.88)$, and the mean FSFI score, $15(\mathrm{SD}=5.2)$.

Sexual dysfunction was observed in $90 \%$ of the patients in our study. Out of the patients with sexual dysfunction, $55 \%$ had recurrent episodes of MDD and $45 \%$ had single-episode MDD. Psychotic symptoms were present in $45 \%$ of the patients. Medical comorbidities were seen in $27.5 \%$, and $27.5 \%$ had passive death wishes.

There was no significant association of sexual dysfunction with education $\left(X^{2}=1.818, p=0.289\right)$, socioeconomic status $\left(x^{2}=0.00, p=0.763\right)$, occupational status $\left(X^{2}=0.423, p=0.521\right)$, type of depression $\left(X^{2}=0.00\right.$, $p=0.763)$, psychotic symptoms $\left(x^{2}=9.47, p=0.100\right)$, medical comorbidities $\left(X^{2}=0.423, p=0.521\right)$, or passive death wishes $\left(X^{2}=0.423, p=0.521\right)$, according to the nonparametric chi-square test. Also, there was no association of sexual dysfunction with patient age $(U=12.5, p=0.516)$, number of episodes $(U=7.00, p=0.211)$, duration of episodes $(U=10.0, p=0.379)$, duration of illness $(U=4.0$, $p=0.095)$, or HAM-D score $(U=9.474, p=0.589)$.

Patients with medical comorbidities showed a significant decrease in the desire subset of the FSFI $(U=11.0, p=0.009)$, however there were no significant associations with the total FSFI score $(U=29.0$, $p=0.312)$ or with the arousal $(U=12.5, p=0.516)$, lubrication $(U=25.0, p=0.179)$, orgasm $(U=31.0$, $p=0.379)$, satisfaction $(U=30.0, p=0.354)$, and pain scores $(U=24.5, p=0.153)$.

Patients who expressed passive death wishes had higher scores on all indicators of sexual function and had a significantly higher score in the orgasm subset of the FSFI (Table 1).

\section{Discussion}

This study found a $90 \%$ prevalence of sexual dysfunction among depressed females in the reproductive age group. Therefore, sexual dysfunction should be a major consideration during the assessment of depression. Our prevalence rate was higher compared to an earlier Indian study on depressed Indian women attending a hospital outpatient department in Mumbai, which had $67.3 \%$ of patients with sexual dysfunction. ${ }^{1}$ Rates of sexual dysfunction vary in different studies depending on differences in the study population and on the types of dysfunction being assessed. In a previous study, spontaneous report of sexual dysfunction by depressed females was $14 \%$, but it rose to a staggering $58 \%$ in the same group when doctors actively asked for the information. ${ }^{10}$ The reasons for the higher prevalence of sexual dysfunction in our study are unclear. The smaller sample may be one reason for the phenomenon. However, this needs to be examined by a study with a larger sample. The study also found that a significant proportion of women (38.09\%) were unwilling to take part in a study involving assessment of their sexual function. Willingness to discuss sexual problems and expectations about sexual performance differ widely among different cultures. ${ }^{11,12}$ This probably may explain the high rate of non-consent, especially as the study comprised mainly housewives attending a rural tertiary care center.

Our study found no significant association of sexual dysfunction with age, socioeconomic status, and occupation. This is in sharp contradiction to an

Table 1 - Association between FSFI scores and passive death wishes

\begin{tabular}{lccc}
\hline Item & Death wish & No death wish & Statistics* \\
\hline FSFI total & 13.70 & 20.98 & $\mathrm{U}=23, \mathrm{p}=0.13$ \\
Desire & 2.52 & 2.90 & $\mathrm{U}=34, \mathrm{p}=0.542$ \\
Arousal & 2.58 & 3.20 & $\mathrm{U}=34, \mathrm{p}=0.542$ \\
Lubrication & 2.75 & 3.60 & $\mathrm{U}=29.5, \mathrm{p}=0.312$ \\
Orgasm & 1.94 & 3.66 & $\mathbf{U}=\mathbf{1 7}, \mathbf{p}=\mathbf{0 . 0 4 1}$ \\
Satisfaction & 2.57 & 3.53 & $\mathrm{U}=25.5, \mathrm{p}=0.179$ \\
Pain & 2.68 & 3.46 & $\mathrm{U}=31.5, \mathrm{p}=0.379$ \\
\hline
\end{tabular}

FSFI $=$ Female Sexual Function Index.

* Mann-Whitney U. 
American study that concluded that sexual dysfunction is associated with various demographic characteristics, including age and educational attainment. ${ }^{12}$ The study also found no relation of sexual dysfunction with type of depression, duration of episode, duration of illness, and psychotic symptoms. There were no comparable studies assessing these variables and further research is needed to validate the findings. Also, there was no association of sexual dysfunction with the severity of depression as assessed by HAM-D, and this is in concordance with an earlier study that observed no association between depression severity and sexual dysfunction. ${ }^{12}$

The study found a significant association between depressive patients with medical comorbidities and diminished sexual desire. Earlier studies have reported that sexual dysfunction is a common sign in patients with a history of depression comorbid with atherosclerosis, hypertension, and diabetes. ${ }^{2,12}$ Patients with passive death wishes had significantly better orgasms according to our study, however there was no difference in the other measures of sexual function. This finding has not been reported elsewhere and needs to be further studied, as the reasons behind this phenomenon are unclear.

In conclusion, the present study shows a high prevalence of sexual dysfunction in women with suspected depression and underscores the importance of screening this population to identify the condition, which may impair marital function and quality of life. The presence of medical illnesses was also associated with sexual dysfunction. Therefore, treatment of medical comorbidities in depressive women should be given specific attention. Finally, the study found a positive association between death wishes and orgasmic function, which needs to be further explored. The major limitation of the study is the small sample size, which prevents the findings from being generalized to the entire population. Further studies with larger samples are needed to estimate the true prevalence of this problem.

\section{Disclosure}

No conflicts of interest declared concerning the publication of this article.

\section{References}

1. Abhivant N, Sawant N. Sexual dysfunction in depressed Indian women attending a hospital out-patient department in Mumbai. Sri Lanka J Psychiatry. 2012;4:10-3.

2. Robert L, Phillips J. Depression and sexual desire. Am Fam Physician. 2000;62:782-6.

3. Basson R, Berman J, Burnett A, Derogatis L, Ferguson D, Fourcroy $J$, et al. Report of the international consensus development conference on female sexual dysfunction: definitions and classifications. J Urol. 2000;163:888-93.

4. Casper RC, Redmond E, Katz MM, Schaffer CB, Davis JM, Koslow $\mathrm{SH}$. Somatic symptoms in primary affective disorders: presence and relationship to the classification of depression. Arch Gen Psychiatry. 1985;42:1098-104.

5. Mathew RJ, Weinman ML. Sexual dysfunctions in depression. Arch Sex Behav. 1982;11:323-5.

6. Angst J. Sexual problems in healthy and depressed patients. Int Clin Psychopharmacol. 1998;13:S1-3.

7. First M, Frances A, Pincus H. DSM-IV-TR guidebook. Washington: American Psychiatric Association; 2004.

8. Sharp R. The Hamilton Rating Scale for Depression. Occup Med (Lond). 2015;65:340.

9. Rosen R, Brown C, Heiman J, Leiblum S, Meston C, Shabsigh R, et al. The Female Sexual Function Index (FSFI): a multidimensional self-report instrument for the assessment of female sexual function. J Sex Marital Ther. 2000;26:191-208.

10. Montejo-González AL, Llorca G, Izquierdo JA, Ledesma A, Bousoño $M$, Calcedo A, et al. SSRI-induced sexual dysfunction: fluoxetine, paroxetine, sertraline and fluvoxamine in a prospective, multicenter, and descriptive clinical study of 344 patients. J Sex Marital Ther. 1997;23:176-94.

11. Bhugra D, De Silva P. Sexual dysfunction across cultures. Int Rev Psychiatry. 1993;5:243-52.

12. Laumann EO, Paik A, Rosen RC. Sexual dysfunction in the United States: prevalence and predictors. JAMA. 1999;281:537-44.

\section{Correspondence:}

Rajmohan Velayudhan

Department of Psychiatry, MES Medical College

Malaparambu, Palachodu P.O.

Perintalmanna, Malappuram, Kerala, India

Tel.: +919895318590

E-mail: rajgiggsmohan@yahoo.com 